\title{
Trauma admissions among victims of domestic violence at a tertiary care hospital in north-western Tanzania: an urgent call to action
}

\author{
PHILLIPO L. CHALYA ${ }^{1 *}$, ANTHONY N. MASSINDE ${ }^{2}$, ALBERT KIHUNRWA ${ }^{2}$, NEEMA M. KAYANGE 3 , KIYETI A. \\ HAULI $^{4}$, ANTHONY KAPESA ${ }^{5}$, WEMAELI MWETENI ${ }^{5}$, SOSPATRO E. NGALLABA ${ }^{5}$ and JAPHET M. GILYOMA ${ }^{1}$ \\ ${ }^{1}$ Department of Surgery, Catholic University of Health and Allied Sciences-Bugando, Mwanza, Tanzania \\ ${ }^{2}$ Department of Obstetrics /Gynecology, Catholic University of Health and Allied Sciences-Bugando, Mwanza, \\ Tanzania \\ ${ }^{3}$ Department of Paediatrics, Catholic University of Health and Allied Sciences-Bugando, Mwanza, Tanzania \\ ${ }^{4}$ Department of Psychiatric, Catholic University of Health and Allied Sciences-Bugando, Mwanza, Tanzania \\ ${ }^{5}$ Institute of Public Health, Catholic University of Health and Allied Sciences-Bugando, Mwanza, Tanzania
}

\begin{abstract}
Background: Despite the growing recognition of domestic violence as a public health and human rights concern, it remains rampant in developing countries and has a negative impact on the victim's health. This study describes the injury characteristics and treatment outcome of trauma associated with domestic violence in north-western Tanzania.

Methods: This was a descriptive prospective study of patients who were managed for domestic violence related trauma at Bugando Medical Centre in Mwanza, Tanzania from April 2009 to March 2014.

Results: A total of 324 patients $(M: F=1: 10.6)$ were studied. Majority of the patients were in the second and third decades of life. The perpetrators were mainly husbands and ex-partners (55.5\%). Suspecting sexual partner being unfaithful was the most common reason given by victims for domestic violence in $63.4 \%$ of cases. Blunt and sharp objects (56.8\%) were the most common weapons used. Gunshot injuries were recorded in $0.6 \%$ of cases. The head/neck was commonly affected in $68.5 \%$. Soft tissue injuries (77.8\%) were the most frequent type of injuries. The majority of patients (65.4\%) sustained mild injuries. Twentythree (7.1\%) patients were HIV positive. Surgical treatment was performed in only $34.6 \%$ of cases. Complication rate was $26.8 \%$. The median hospital stay was 12 days. Mortality rate was $6.5 \%$. The main predictors of mortality were advanced age ( $>60$ years), late presentation, severity of injury, severe head injury, HIV seropositivity, low CD 4 count ( $<200$ cells), surgical site infection $(p<0.001)$. More than twothirds of patients were lost to follow up.

Conclusion: Domestic violence related trauma remains rampant in northwestern Tanzania and contributes significantly to high morbidity and mortality. Urgent preventive measures targeting at reducing the occurrence of domestic physical violence is necessary to reduce the morbidity and mortality resulting from these injuries.
\end{abstract}

Keywords: Domestic violence, physical trauma, injury characteristics, treatment, outcome, Tanzania

\section{Introduction}

Domestic violence is recognized as an important social and public health problem that involves people in intimate relationships and may be perpetrated by either men or women (Johnson \& Leonne, 2005). It is a serious human rights in many parts of the world and its consequences can be devastating (Trevillion et al., 2012). The term "domestic violence" encompasses physical, sexual and psychological violence or any combination of these acts (Krantz \& Garcia-Moreno, 2005). Globally, domestic violence is the most common type of violence against women and its worldwide prevalence is estimated to be between 10 and 75\% (Garcia-Moreno, 2000; WHO, 2001; Uthman et al., 2009). Existing reports also demonstrate that domestic violence is prevalent among men, though to a lesser degree (Walton et al,, 2009; Cunradi, 2009; Ansara \& Hindin, 2010) and is more frequent among men who have sex with men (Stephenson et al., 2010) and those who abuse alcohol and drugs (Gilchrist et al., 2010; Zaleskiet al., 2010). Women are often targets of domestic violence because of their unequal status in society (Chrisler \& Ferguson, 2006). Domestic violence usually involves the infliction of bodily injury, accompanied by verbal threats and harassment, emotional and psychological abuse, or the destruction of property, and it is employed usually as a means of coercion, control, revenge, or punishment of a person with whom the abuser is or has been involved in an intimate relationship (Ellsberg et al., 2008). 
Numerous risk factors have been associated with female victimization from domestic violence, including socio- demographic variables (Cunradi, 2009; Breiding et al., 2009; Deyessa et al., 2010), length of stay in a relationship with a male partner, partners' substance abuse, early intercourse, and childhood experiences of sexual abuse and/or physical abuse in the home (McCloskey et al., 2005). These risk factors demonstrate that domestic violence is multidimensional, and as conceptualized in a socio-ecological framework, points to the important interplay of individual, family, community, and societal level factors (Andersson et al., 2007). The perceptions of domestic violence vary based on region, religion, and class. For example, the Kurya tribe in Tanzania view wife battering as a "sign of love" that should be encouraged as evidenced with the statement "If you are not yet beaten by your husband then you do not know the joy of marriage and that means you are not yet married".

Victims of domestic violence often access the health care system, across the range from emergency departments to clinics and private practices, for treatment of injuries and illnesses resulting from the physical and emotional trauma of domestic violence (Yoshihama et al., 2007). Domestic physical violence is the most common form of domestic violence in Tanzania and women are the most common victims (Chalya \& Gilyoma, 2012). Injuries related to domestic physical violence are usually admitted to the emergency services, and vary from minor abrasions and bruises to multi-system trauma that can result in death (Andersson et al., 2007). Injuries may result from being punched, hit, kicked, burned, stabbed, thrown down stairs, thrown out of a moving car, shot or struck with objects (Andersson et al., 2007; Chalya \& Gilyoma, 2012). Traumatic injuries associated with domestic physical violence include lacerations, contusions, fractures, burns, intra-abdominal injuries, stab wounds and gunshot wounds (Andersson et al., 2007).

Despite widespread reports of domestic violence in low income countries including Tanzania, there are no published studies that examine the patterns of injury and outcome of trauma resulting from domestic physical violence. Domestic violence related injuries appear to be a hidden public health problem of epidemic proportion and constitute significant percentage of cases seen at the accident and emergency department of most hospitals in Tanzania. Evidences from clinical practice in our setting have shown that incidence appears to be on the increase due to social, cultural, and economic factors. A sudden increase in the number of trauma admissions among victims of domestic violence in recent years at Bugando Medical Centre in Mwanza, Tanzania, prompted analysis this problem. This study was conducted to describe the experience in the management of trauma associated with domestic physical violence, outlining the injury characteristics and treatment outcomes.

\section{Materials and methods}

\section{Study setting and population}

This was a descriptive prospective study of patients who were managed for domestic violencerelated trauma at Bugando Medical Centre over a period of five years from April 2009 to March 2014. Bugando Medical Centre is located in Mwanza city, along the shores of Lake Victoria in north-western Tanzania. It is a tertiary care and teaching hospital for the Catholic University of Health and Allied Sciences-Bugando (CUHAS-Bugando) and has 1000 beds.

The study population consisted of all patients who were managed for domestic violencerelated trauma at the Accident and Emergency ( $\&$ \&) department of Bugando Medical Centre during the study period. Patients who presented in an unconscious state and those who were under 18 years of age, their parents, guardian or relatives had to consent on their behalf. Patients who failed to give proper information and those who had no relative to consent for the study were excluded from the study. Patients who failed to consent for HIV testing were also excluded from the study. Domestic physical violence in this study was defined as the use of physical force with or without weapon to cause body harm within the family or household. 
Recruitment of patients to participate in the study was done at the A \& E department. Patients were screened for inclusion criteria and those who met the criteria were consecutively enrolled into the study. Patients with severe injuries were first resuscitated in the $A \& E$ department according to Advanced Trauma Life Support (ATLS). From the A \& E department, patients were taken into the surgical wards or the intensive care unit (ICU) from where necessary investigations were completed and further treatment was instituted.

The severity of injury was determined using the Kampala Trauma Score II (KTS II) (Mutooro et al., 2010). Severe injury consisted of a KTS II $\leq 6$, moderate injury 7-8, and mild injury 9-10. Patients with head injuries were classified according to Glasgow Coma Scale (GCS) into: severe (GCS 3-8), moderate (GCS 9-12) and mild (GCS 13-15). Routine investigations including hematological (hemoglobin, blood grouping and cross-matching) and biochemical (serum creatinine and serum electrolytes) were performed on admission. Patients were also screened for HIV testing using Tanzania HIV Rapid Test Algorithm (Lyamuya et al., 2009) and CD 4+ count using FACS or FACSCALIBUR from BD Biosciences USA. A determination of CD 4 count was only performed in HIV positive patients. Radiological investigations (X-rays of the chest and abdomen, abdominal ultrasound and skull/brain Computerized tomography scan) were also performed on admission. All patients were followed up till discharged or death. This information was collected using a pre-tested questionnaire. Study variables included socio-demographic data (age, sex, education, area of residence, occupation), circumstances of the injury (i.e. time of injury, place of injury, reasons and contributing factors for the injury, weapon used, pre-hospital care, timing of medical care), characteristics of injury (mechanism of injury, body region affected, type of injury, severity of injury), treatment parameters and outcome measures (length of hospital stay, mortality and complications).

\section{Data analysis}

Statistical analysis was performed using the Statistical Package for Social Sciences version 17.0 for Windows (SPSS, Chicago, IL, USA). The median (and interquartile range) and ranges were calculated for continuous variables, whereas proportions and frequency tables were used to summarize categorical variables. The chi-square $\left(\chi_{2}\right)$ test was used to test for the significance of association between independent (predictor) and dependent (outcome) variables in the categorical variables. Significance was considered for $p<0.05$. Variables that were found to be statistically significant on univariate analysis were subjected to multivariate logistic regression analysis to determine predictor variables that predicted the outcome.

\section{Ethical consideration}

Ethical approval to conduct the study was obtained from the joint institutional ethic review committee of the Catholic University of Health and Allied Sciences-Bugando and Bugando Medical Centre before the commencement of the study. Patients who met the inclusion criteria were requested to sign a written informed consent for the study and HIV testing before being enrolled into the study.

\section{Results}

A total of 324 patients were admitted due to domestic violence-related injuries during the study period. Of the 324 patients, 296 (91.4\%) were females and 28 (8.6\%) males with a male to female ratio of 1: 10.6. The age of patients at presentation ranged from 4 to 82 years with a mean of 28 years (interquartile range: 26 to 30 years). The peak age incidence was in the age group of 21-30 years, which constituted $42.4 \%$ of all cases. One hundred thirty-eight (42.6\%) were married, 102(31.4\%) single and $72(20.5 \%)$ either separated or divorced. Twelve (3.7\%) were children aged 10 years and below. Out of the 296 patients, 24 (8.1\%) were pregnant, of which eleven presented with miscarriages. The majority of patients, $244(75.3 \%)$ had primary or no formal education and most of them, 267 (82.4\%) had no employment. Two hundred fifty-eight (79.6\%) patients came 
from rural areas around Mwanza City. The majority of patients, 302 (93.2\%) belonged to the low socioeconomic class and only $22(6.8 \%)$ victims were from higher classes. Only $21(6.5 \%)$ of the victims had definable source of private or governmental health care insurance at the time of their injury.

Table 1: Reasons given by victims for domestic physical violence

\begin{tabular}{lll}
\hline Reasons & Frequency $(\mathbf{n = 2 4 6})^{*}$ & Percentage \\
\hline Suspect sexual partner unfaithful & 162 & 65.9 \\
Arguments over money or care & 156 & 63.4 \\
Disrespect to husband' in laws & 103 & 41.9 \\
Inability to satisfy sexual demands & 98 & 39.8 \\
Husband drunk & 93 & 37.8 \\
Neglect of housework & 56 & 22.8 \\
Child used abusive words to parents/relative/ care taker & 7 & 2.8
\end{tabular}

*Victims could report more than one reason

The majority of patients, 302 (93.2\%) were injured at the victims residence, followed by drinking places and along the street in $12(3.7 \%)$ and $8(2.5 \%)$ patients, respectively. In two (0.6\%) patients, injuries occurred in other places. History of alcohol consumption either by the victim or perpetrator was reported in $212(65.2 \%)$ of the cases and it was the perpetrator of the violence who was often under the influence of alcohol. The attacker/ perpetrator was known to all the victims and included husband/ex-partners, boyfriends, relatives/members of the family and parents in $180(55.5 \%), 80(24.7 \%), 40(12.3 \%)$ and $24(7.4 \%)$, respectively. Eighty-seven $(26.9 \%)$ of the victims reported instances of domestic violence perpetuated against them while $237(73.1 \%)$ indicated they had never reported. Out of 87 victims who reported the instances, $44(50.6 \%)$ reported to their family members while $14(16.1 \%)$ reported to religious leaders and only $6(6.9 \%)$ victims reported to the spouse employer. Only 23 (26.4\%) victims had the courage to report the instances to police. Suspect sexual partner unfaithful was the most common reason given by victims for domestic physical violence in $65.9 \%$ of cases (Table 1 ).

Table 2: Distribution of patients according to the site and type of injury

\begin{tabular}{llll}
\hline Variables & Category & Frequency & Percentages \\
\hline Site of injury & Head/neck/maxillofacial & 222 & 68.5 \\
Upper limbs & 115 & 35.5 \\
Lower limbs & 52 & 16.0 \\
Chest & 48 & 14.8 \\
Abdomen & 42 & 13.0 \\
Genitalia & 34 & 10.5 \\
Spine & 3.1 & 2.2 \\
Eyes & 10 & 0.9 \\
Ocular & 7 & 29.0 \\
Multiple sites & 3 & 77.8 \\
Soft tissue injuries & 94 & 29.6 \\
Fractures / dislocations & 252 & 3.4 \\
Miscarriages & 96 & 3.4 \\
Pneumothorax & 11 & 3.1 \\
Haemothorax & 11 & 2.8 \\
Pneumohaemothorax & 10 & 2.8 \\
Visceral abdominal injuries & 9 & 2.5 \\
Intracranial haematomas & 9 & 2.2 \\
Burn injuries & 8 & 0.9 \\
\hline
\end{tabular}


Blunt objects (such as stones, iron bars, sticks and bottles) and sharp objects (machetes, knives, spears and screw drivers) were the most common weapons through which violence was inflicted accounting for 184 (56.8\%) of cases. Fists, slaps and kicks were used to inflict domestic violence in $97(29.9 \%)$ of cases. The use of guns to inflict domestic violence was recorded in $2(0.6 \%)$ of cases. Burns including scald ( 4 patients), flame ( 2 patients) and chemical (1 patient) were the means through which violence was inflicted in $7(2.2 \%)$ of cases. Rape was reported in $34(10.5 \%)$ of the victims. Blunt injuries were the most common mechanism of injuries accounting for $215((66.2 \%)$ followed by either penetrating injuries (cut wounds, stabbing, gunshot) or both in $102(31.5 \%)$ patients. Burn was the mechanism of injury in $7(2.2 \%)$ of victims. The head/ neck/ maxillofacial were the most common body region affected accounting for $68.5 \%$ of cases. Soft tissue injuries (wounds) were the most frequent type of injuries affecting $77.8 \%$ of cases (Table 2 ).

The majority of injuries occurred during evening and night hours (18:00 and 21:00 hours) in $311(95.7 \%)$ of cases and in the remaining $14(4.3 \%)$ patients occurred during the day. The majority of victims, 245 (75.6\%) presented after 24 hours of the injury and the remaining 79 (24.6\%) presented within 24 hours of the injury. Following the injury events, none of the patients received any pre-hospital care and majority of them, $279(86.1 \%)$ were brought to the A \& E department by relatives, friends or Good Samaritan, 42 (13.0\%) by police and only three $(0.9 \%)$ patients were brought in by ambulance.

According to Kampala Trauma Score II (KTS II) (Table 3), the majority of patients sustained mild injuries (KTS II = 9-10) in $212(65.4 \%)$. Moderate injuries (KTS II = 7-8) and severe injuries (KTS II $\leq 6)$ were recorded in $69(21.3 \%)$ and $43(13.6 \%)$ patients respectively. Of the 222 patients who sustained head injuries, $166(74.8 \%)$ had mild head injuries and the remaining 56 (25.2\%) had moderate to severe head injuries.

All patients in this study were tested for HIV infection and revealed positive results in 23 (7.1\%) patients. CD 4+ count among HIV positive patients was available in only 17 patients and ranged from 132 cells $/ \mu$ lo 748 cells/ $\mu$ l with the median CD $4+$ count of 278 cells $/ \mu$ l. A total of six (35.3\%) HIV positive patients had CD4+ count below 200 cells/ $\mu$ land the remaining 11 (64.7\%) patients had CD4+ count of $\geq 200$ cells/ $\mu$ l.

Table 3: Kampala Trauma Score (KTS II) description

\begin{tabular}{|c|c|c|}
\hline & Description & Score \\
\hline \multirow[t]{3}{*}{ A } & Age in years & \\
\hline & $5-55$ & 1 \\
\hline & $<5$ or $>55$ & 0 \\
\hline \multirow[t]{4}{*}{ B } & Systolic Blood Pressure on admission & \\
\hline & More than $89 \mathrm{~mm} \mathrm{Hg}$ & 2 \\
\hline & Between $89-50$ mm Hg & 1 \\
\hline & Equal or below $49 \mathrm{~mm} \mathrm{Hg}$ & 0 \\
\hline \multirow[t]{4}{*}{ C } & Respiratory rate on admission & \\
\hline & $0-29 /$ minute & 2 \\
\hline & $30+$ & 1 \\
\hline & $<$ or $=9 /$ minutes & 0 \\
\hline \multirow[t]{5}{*}{ D } & Neurological status & \\
\hline & Alert & 3 \\
\hline & Responds to verbal stimuli & 2 \\
\hline & Responds to painful stimuli & 1 \\
\hline & Unresponsive & 0 \\
\hline \multirow[t]{4}{*}{ E } & Score for serious injuries & \\
\hline & None & 2 \\
\hline & One injury & 1 \\
\hline & More than one & 0 \\
\hline
\end{tabular}

Kampala Trauma Score total = A+B+C+D+E; Key: KTS II $\leq 6$ = Severe injury; KTS II 7-8 = Moderate injury; KTS II 9-10 = Mild injury. 
Out of 324 patients, 112 (34.6\%) were treated surgically and the remaining $212(65.4 \%)$ were treated conservatively (non-surgical) with wound dressing, antibiotics, analgesics, tetanus toxoid etc. All patients were administered antibiotics of varying nature and analgesics at the $\mathrm{A}$ and $\mathrm{E}$ department. Two hundred forty eight (76.5\%) patients received tetanus toxoid. Blood transfusion was given to thirty-eight (11.7\%) patients. Of the patients who were treated surgically, surgical wound debridement was the most common procedure performed in $96.4 \%$ of patients (Table 4 )

Table 4: Distribution of patients according to the type of surgical procedures performed $(\mathrm{N}=112)$

\begin{tabular}{lll}
\hline Surgical procedure & Frequency & Percentages \\
\hline Surgical wound debridement & 108 & 96.4 \\
Treatment of fractures/ dislocations & 92 & 82.1 \\
Underwater seal drainage & 22 & 19.6 \\
Evacuation & 11 & 9.8 \\
Exploratory laparotomy & 9 & 8.0 \\
Craniotomy / burr holes /elevation of depressed skull fractures & 7 & 6.3 \\
Skin grafting & 4 & 3.6 \\
\hline
\end{tabular}

A total of 33 complications were recorded in $30(26.8 \%)$ patients, the commonest being surgical site infections accounting for $36.4 \%$ of patients (Table 5). In the present study, the rate of surgical site infections was found to be significantly higher in HIV positive patients than in non HIV patients $(p=0.003)$. Also higher rate of surgical site infections was observed among HIV patients with CD 4 count below 200 cells $/ \mu l(p=0.001)$.

The overall length of hospital stay (LOS) ranged from 1 to 54 days with a median of 12 days. The median LOS for non-survivors was 6 days (range 1-14 days). Patients who developed post-operative complications and those who had burn injuries and long bone fractures stayed longer in the hospital and this was statistically significant $(P=0.012)$.

Table 5: Distribution of patients according to postoperative complications $(\mathrm{N}=33)$

\begin{tabular}{lll}
\hline Complications & Frequency & Percentages \\
\hline Surgical site infections & 12 & 36.4 \\
Complications of fracture treatment & 9 & 27.2 \\
Complications of abdominal surgery & 4 & 12.1 \\
Empyema thoracis & 2 & 6.1 \\
Urinary tract infections & 2 & 6.1 \\
Pneumonia & 2 & 6.1 \\
Brain abscess & 1 & 3.0 \\
Graft failure & 1 & 3.0 \\
\hline
\end{tabular}

In this study, twenty-one patients died in hospital, giving a mortality rate of $6.5 \%$. According to multivariate logistic regression analysis, advanced age ( $>60$ years) $(\mathrm{OR}=2.5,95 \% \mathrm{Cl}(1.2-4.8), \mathrm{p}=$ 0.012 ), late presentation ( $\geq 24$ hours) $(\mathrm{OR}=5.4,95 \% \mathrm{Cl}(2.8-6.9), \mathrm{p}=0.011)$, severity of injury (KTS $\mathrm{II} \leq 6)(\mathrm{OR}=2.4,95 \% \mathrm{Cl}(1.3-6.8), \mathrm{p}=0.020)$, severe head injuries $(\mathrm{OR}=8.1,95 \% \mathrm{Cl}(2.6-12.7), \mathrm{p}=$ $0.014)$, HIV positivity ( $O R=2.9,95 \% \mathrm{Cl}(1.1-8.8), \mathrm{p}=0.012)$, low $\mathrm{CD} 4$ count $(<200 \mathrm{cells} / \mu \mathrm{l})(\mathrm{OR}=$ 2.9, $95 \% \mathrm{Cl}(1.9-7.5), \mathrm{p}=0.001)$, surgical site infection ( $\mathrm{OR}=4.5,95 \% \mathrm{Cl}(1.1-8.6), \mathrm{p}=0.021)$ were the main predictors of mortality.

Out of 303 survivors, 283 (93.4\%) were discharged well without permanent disability, 12 (4.0\%) were discharged against medical advice and the remaining 8 (2.6\%) were discharged with permanent disability such as limb/finger amputation ( 3 patients), paraplegia ( 2 patients) and ocular loss, posttraumatic epilepsy and hearing loss in 1 patient each respectively. Of the 303 survivors, 102 (33.7\%) were available for follow up at six to 12 months after discharge and the remaining $201(66.3 \%)$ patients were lost to follow up. 


\section{Discussion}

Domestic violence is a global problem and its prevalence in Sub-Saharan Africa ranks high and affects a large proportion of the population - with the majority of those directly experiencing such violence being women and the majority perpetrating it being men (Johnson \& Leonne, 2005). In this study, an average of 65 cases of domestic violence injuries annually was observed during the five years of study. However, the rate of these injuries in the present study may be underestimated due to unreported patients, patients who died at scene or who did not reach our hospital because of treatment of minor injuries in private hospitals. A better picture of the magnitude of violence related injuries in our setting requires comprehensive data including police records, hospital admissions, and mortuary records. Better data could support useful policy guidance and help abate these injuries and their related morbidity and mortality. Injury surveillance is needed to be able to detect cases of domestic violence in our setting.

The age and gender disposition of patients in this study is similar to findings reported in other studies elsewhere (Trevillion et al., 2012). The female preponderance in the present study could be attributable to by the culture and traditional gender norms that support wife beating within the community. In the present study, the majority of patients were injured at the victim's residence and the perpetrators of the violence were mainly husbands and ex-partners. It is likely that violence between partners in a relationship may be triggered by numerous factors, including stressful or frustrating life situations such as loss of a job, financial problems or pregnancy; role changes that may impact the attacker's sense of control (Itimi et al., 2014). However, in the present study, suspected a sexual partner of being unfaithful was the most common reason given by victims for domestic physical violence in approximately two-thirds of cases. This was at variance with what was reported in Uganda where woman neglected a household chore was the most common reason for domestic physical violence (Koening et al., 2003). We were unable to establish the reason for this difference.

Several studies in developing countries have found a strong association between alcohol "misuse" and "abuse" and the risk of domestic violence (Gilchrist et al., 2010). In this study, the history of alcohol "misuse" and "abuse" either by the victim or perpetrator was reported in about two thirds of the cases. Alcohol "misuse" and "abuse" is associated with increased risk of all forms of domestic violence as it is thought to reduce inhibitions, cloud judgment and impair the ability to interpret social cues (Caetano et al., 2001).

Domestic violence has been reported to be more prevalent in people with low socioeconomic status (Deyessa et al., 2010). This observation is reflected in our study where more than ninety percent belonged to the low socioeconomic class and most of them had either primary or no formal education and were unemployed. The majority of patients in this study came from the rural areas located a considerable distance from the study area and more than eighty percent of them had no identifiable health insurance. This observation has an implication on accessibility to health care facilities and awareness of the disease.

In developing countries, domestic violence is one of the most chronically underreported crimes (Koening et al., 2003). Only approximately one-quarter of all physical assaults perpetuated against females by intimate partners are reported to the police (Koening et al., 2003). This is reflected in our study, in which only a quarter of the victims reported the instances to police. The low rate of reporting the instances to police in the current study may be related to fear associated with consequences of domestic violence such as stigma, shame or other social and cultural factors that deter women from discussing episodes of violence. Also many victims may not report to the law enforcement agents for fear of reprisal from abusers or the belief that the police and the judicial system cannot help.

The lack of advanced pre-hospital care and ineffective ambulance system for transportation of patients to hospitals are a major challenges in providing care for trauma patients in most developing countries and have contributed significantly to poor outcome of these patients (Kobusingye, 2008). This is reflected in our series where none of none of the 
patients received any pre-hospital care and only three (0.9\%) patients were brought in by ambulance. More than three quarters of patients in this study presented late ( $>24$ hours) which is in keeping with other studies done in developing countries (Kobusingye, 2008; Chalya \& Gilyoma., 2012). We could not establish in this study the reasons for this delayed presentation.

In agreement with other studies (Grisso et al., 1999; Adotey \& Jebin, 2002; Chalya \& Gilyoma, 2012), blunt objects such as stones, iron bars, sticks and bottles and sharp objects such as machetes, knives, axes and screw drivers were the most common weapons used in the present study. This is contrary to Mugala \& Imataa (2007) in Zambia who reported that fists, slaps and kicks were the means through which violence was inflicted. A better knowledge of the type of weapon or means through which violence is inflicted is of great importance for medico-legal purposes. The head and neck were the most common body region injured which is consistent with other studies on assault victims (Adotey \& Jebin, 2002; Chalya \& Gilyoma, 2012). This is due to the preference and accessibility of these regions as a target for assailants. Upper limb was also commonly injured reflecting the tendency of victims to defend themselves with their hands during the assault.

There are increasing studies from Africa that report on the relationship between HIV infection and domestic violence (Maman et al., 2002; Lary et al., 2004; Andersson et al., 2008; Prabhu et al., 2011). In the present study, HIV seroprevalence among victims of domestic violence was 7.1\%, a figure which is higher than that in the general population in Tanzania (Prabhu et al., 2011). Potential ways in which HIV infection may be linked to domestic violence, based on studies mainly emerging from Africa include: physical vaginal trauma from forced sex; limited capability to negotiate safer sex due to partner violence or threat of it; violence following disclosure of a positive HIV result and perpetrators more likely to engage in risky sexual behavior (Lary et al., 2004; Andersson et al., 2008; Prabhu et al., 2011). In this study, physical vaginal trauma from forced sex was reported in $10.5 \%$ of cases. We could not establish the reasons for the HIV seroprevalence among victims of domestic violence in this study.

In this study, surgical treatment was performed in only one-third of the patients. The low rate of surgical procedures in the current study is attributable to the fact that the majority of patients sustained mild injuries which were treated conservatively (non-surgical) with wound dressing, antibiotics cover, analgesics, tetanus toxoid etc.

As reported by authors in other studies (Prabhu et al., 2011; Chalya \& Gilyoma, 2012), surgical site infection was the most common complication in this study. The rate of surgical site infections was found to be significantly higher in HIV positive patients with CD 4 count below 200 cells/ $\mu \mathrm{l}$. The overall median duration of hospital stay in the present study was 12 days which is higher than that reported by Chalya \& Gilyoma (2012). Patients who developed post-operative complications and those who had burn injuries and long bone fractures stayed longer in the hospital. The mortality rate in this study was significantly associated with advanced age, late presentation, severity of injury, severe head injury, HIV seropositivity, low CD 4 count, surgical site infection. Self discharge by patient against medical advice and large number of loss to follow up a recognized problem in our setting that need to be addressed.

This study has a number of limitations. The findings from this study cannot be inferred to all women in Tanzania as the study included a hospital-based sample of patients who were treated at Bugando Medical Centre only. Underestimating of the magnitude of the problem might have occurred due to unreported patients, patients who died at scene or who did not reach our hospital because of treatment of minor injuries in private hospitals but who suffer from psychological abuse which can evidence itself somatically. Large number of loss to follow up was also a major limitation in this study.

In conclusion, this study demonstrates that trauma resulting from domestic physical violence is a major but neglected public health problem of epidemic proportion and contributes significantly to high morbidity and mortality among the victims in this part of Tanzania. Urgent preventive measures targeting at reducing the occurrence of domestic physical violence is necessary to reduce the morbidity and mortality resulting from these injuries. 


\section{Acknowledgements}

The authors thank all those who participated in the preparation of this manuscript, and those who were involved in the care of our study patients.

\section{References}

Adotey, J. M. \& Jebin, N. J. (2002) The Pattern of Stab Injuries in Port Harcourt, West African Journal of Medicine 21, 223-225.

Andersson, N., Cockcroft, A., Shea, B. (2008) Gender-based violence and HIV: relevance for HIV prevention in hyperendemic countries of southern Africa. AIDS 22, S73-86.

Andersson, N., Ho-Foster, A., Mitchell, S., Scheepers, E. \& Goldstein, S. (2007) Risk factors for domestic physical violence: national cross-sectional household surveys in eight southern African countries. BMC Womens Health 7:11.

Ansara, D.L. \& Hindin, M.J. (2010) Formal and informal help-seeking associated with women's and men's experiences of intimate partner violence in Canada. Social Science \& Medicine 70, 1011-1018.

Breiding, M.J, Ziembroski, J.S. \& Black, M.C. (2009) Prevalence of rural intimate partner violence in 16 US states, 2005. Journal of Rural Health 25, 240-246.

Caetano, R., Schafer, J. \& Cuinradi, C.B. (2001) Alcohol related intimate partner violence among White, Black and Hispanic couples. Alcohol Research Health 25, 58-65.

Chalya, P. \& Gilyoma J.M. (2012) The burden of intentional injuries in Mwanza City, north-western Tanzania: a tertiary hospital survey. Tanzania Journal of Health Research 14, 204-211.

Chrisler, J.C. \& Ferguson, S. (2006) Violence against women as a public health issue. Annals of New York Academic Science 1087, 235-249.

Cunradi, C.B. (2009) Intimate partner violence among Hispanic men and women: the role of drinking, neighborhood disorder, and acculturation-related factors. Violence and Victims 24, 83-97.

Deyessa, N., Berhane, Y., Ellsberg, M., Emmelin, M., Kullgren, G. \& Hogberg, U. (2010) Violence against women in relation to literacy and area of residence in Ethiopia. Global Health Action 25 .

Efetie, E.R. \& Salami, H.A. (2007) Domestic violence on pregnant women in Abuja, Nigeria. Journal of Obstetrics \& Gynaecology 27, 379-379.

Ellsberg, M., Jansen, H.A., Heise, L., Watts, C.H. \& Garcia-Moreno, C. (2008) WHO Multi-country Study on Women's Health and Domestic Violence against Women Study Team. Intimate partner violence and women's physical and mental health in the WHO multi-country study on women's health and domestic violence: an observational study. Lancet 37, 1165-1172.

Garcia-Moreno, C. (2000) Violence against women: international perspectives. American Journal of Preventive Medicine 19, 330-333.

Gilchrist, G., Hegarty, K., Chondros, P., Herrman, H. \& Gunn, J. (2010) The association between intimate partner violence, alcohol and depression in family practice. BMC Family Practice 11: 72.

Grisso, J.A., Schwarz, D.F., Hirschinger, N., Sammel, M., Brensinger, C., Santanna, J., Lower, R.A., Anderson, E., Shaw, L.M., Bethel, C.A. \& Teeple, L. (1999) Violent Injuries among women in an urban area. New England Journal of Medicine 341, 1899-1905.

Itimi, K., Dienye, P.O. \& Gbeneol, P.K. (2014) Intimate partner violence and associated coping strategies among women in a primary care clinic in Port Harcourt, Nigeria. Journal of Family Medicine and Primary Care 3, 193-198.

Jewkes, R.K., Dunkle, K., Nduna, M. \& Shai, N. (2010) Intimate partner violence, relationship power inequity, and incidence of HIV infection in young women in South Africa: a cohort study. Lancet 376, 41-48. 
Kobusingye, O.C. (2008) Violence and Injuries: What Africa should do? African Health Monitor 3740.

Koening, M.A., Lutalo, T., Zhao, F., Nalugoda, F., Wambwe-Mangen, F., Kiwanuka, N., Wagman, J., Serwadda, D., Wawer, M. \& Gray, R. (2003) Domestic violence in rural Uganda: evidence from a community-based study. Bulletin of the World Health Organization 81, 53-60.

Krantz, G. \& Garcia-Moreno, C. (2005) Violence against women. Journal of Epidemiology and Community Health 59, 818-821.

Lary, H., Maman, S., Katebalila, M., McCauley, A. \& Mbwambo, J. (2004) Exploring the association between HIV and violence: young people's experiences with infidelity, violence and forced sex in Dar es Salaam, Tanzania. International Family Planning Perspectives 30, 200-206.

Lyamuya, E.F., Aboud, S., Urassa, W.K., Sufi, J., Mbwana, J., Ndungulile, F. \& Massambu C. (2009) Evaluation of rapid HIV assays and development of national rapid HIV test algorithms in Dar es Salaam, Tanzania. BMC infectious Diseases 9: 19.

Maman, S., Mbwambo, J.K, Hogan, N.M., Kilonzo, G.P., Campbell, J.C., Weiss, E. \& Sweat, M.D. (2002) HIV positive women report more lifetime partner violence: findings from a voluntary counseling and testing clinic in Dar es Salaam, Tanzania. American Journal Public Health92, 1331-1337.

McCloskey, L.A, Williams, C. \& Larsen, U. (2005) Gender inequality and intimate partner violence among women in Moshi, Tanzania. International Family Planning Perspectives 31, 124-130.

Mugala, D.D. \& Imataa, D. (2007) Admissions for physical violence in Chingola, Zambia. East and Central African Journal of Surgery 12, 68-73.

Mutooro, S.M., Mutakooha, E. \& Kyamanywa, P. (2010) A comparison of Kampala trauma score II with the new injury severity score in Mbarara University Teaching Hospital in Uganda. East and Central African Journal of Surgery 15, 62-70.

Mutto, M., Lett, R., Lawoko, S., Nansamba, C. \& Svanstrom, L. (2010) Intentional injuries among Ugandan youth: a trauma registry analysis. Injury Prevention 16, 333-336.

Oladepo, O., Yusuf, O.B. \& Arulogun, O.S. (2011) Factors associated with gender based violence in selected states in Nigeria. African Journal of Reproductive Health 15, 78-86.

Prabhu, M., Mchome, B., Ostermann, J., Itemba, D., Njau, B., Thielman, N. , KIWAKUKI-Duke VCT Study Group (2010)Prevalence and correlates of intimate partner violence among women attending HIV voluntary counseling and testing in northern Tanzania, 2005-2008. International Journal of Gynecology and Obstetrics 113, 63-67.

Stephenson, R., Khosropour, C. \& Sullivan, P. (2010) Reporting of Intimate Partner Violence among Men Who Have Sex with Men in an Online Survey. Western Journal of Emergency Medicine 11, 242-6.

Trevillion, K., Oram, S., Feder, G. \& Howard, L.M. (2012) Experiences of domestic violence and mental disorders: a systematic review and meta-analysis. PLoS One 7, e51740.

Uthman, O.A., Moradi, T. \& Lawoko, S. (2009) The independent contribution of individual, neighbourhood, and country-level socioeconomic position on attitudes towards intimate partner violence against women in sub-Saharan Africa: a multilevel model of direct and moderating effects. Social Science and Medicine 68, 1801-1809.

WHO (2001) The World Health Report 2001-Mental Health: New Understanding, New Hope. World Health Organization, Geneva.

Walton, M.A., Murray, R., Cunningham, R.M., Chermack, S.T., Barry, K.L, Booth, B.M., Ilgen, M.A., Wojnar, M. \& Blow, F.C. (2009) Correlates of intimate partner violence among men and women in an inner city emergency department. Journal of Addictive Diseases 28, 366-381.

Yoshihama, M., Horocks, J. \& Kamano, S. (2007) Experiences of intimate partner violence and related injuries among women in Yokohama, Japan. American Journal Public Health 97, 232240. 
Zaleski, M., Pinsky, I., Laranjeira, R., Ramisetty-Mikler, S. \& Caetano, R. (2010) Intimate partner violence and contribution of drinking and sociodemographic: the Brazilian National Alcohol Survey. Journal of Interpersonal Violence 25, 648-665.

Valladares, E., Ellsberg, M., Peña, R., Högberg, U. \& Persson, L.A. (2002) Physical partner abuse during pregnancy: A risk factor for low birth weight in Nicaragua. Obstetrics and Gynecology 100, 700-705. 